\title{
Federal Information Processing Standards
}

National Cancer Institute

\section{Source}

National Cancer Institute. Federal Information Processing Standards. NCI Thesaurus. Code C71327.

Standards developed by the National Institute of Standards and Technology (NIST) to address Federal requirements for the interoperability of different systems, for the portability of data and software, and for computer security. 